Thirdly, the absence of poliomyelitis from a community may lead to a false sense of security.

The oral poliovaccine used in Britain contains all three types of poliovirus. ${ }^{7}$ The recommended schedule is three doses of vaccine at intervals of about 4 to 6 weeks, starting at 6 to 7 months, after the primary course of triple vaccine has been completed. Alternatively, both triple vaccine and oral poliovaccine may be given simultaneously, the course starting at 3 months. This has the advantage of being easier from the administrative point of view and may result in a greater number of children being immunized. At present there is insufficient evidence to decide whether it is necessary to offer a reinforcing dose of oral poliovaccine in the second year of life, but when primary immunization has been completed before the baby's sixth month it is probably desirable to give a further dose of oral vaccine at 18 to 24 months at the time of the important reinforcing dose of triple vaccine. In order to ensure that immunity is maintained it is most important to give a reinforcing dose of oral vaccine at the time of school entry. This has the double advantage of maintaining immunity and providing a check on those who have escaped the primary immunization course in infancy. Adults who are likely to be at special risk, such as those travelling abroad to epidemic areas, would be well advised to take advantage of the simplicity of administration of oral poliovaccine in having a booster dose. This applies particularly to persons who were immunized with inactivated vaccine some years previously.

There are few contraindications to oral poliovaccine. Like any immunization procedure, it should be postponed if the patient is ill. Patients on corticosteroid therapy need special consideration. It is probably best to withhold it from those on long-term therapy in high dosage, but each case should be considered individually. It is also advisable to withhold oral vaccine during the first four-months of pregnancy, though there is no evidence whatever that the live virus vaccine has any deleterious effect on the foetus. Immunization is better carried out before, rather than during, pregnancy. Few vaccines produce so few reactions as does oral poliovaccine, and its ease of administration recommends it to most young patients.

Continued vigilance is required to ensure that immunity against poliomyelitis is maintained, and all members of the profession, medical officers of health, general practitioners, and hospital doctors can help to see that it is.

\section{Research in Migraine}

The recent announcement of the formation of a Migraine Trust under distinguished medical guidance raises hopes that research into this baffling disease will be intensified. Lord Brain is the chairman of the Trust and Dr. Macdonald Critchley is one of the other trustees. ${ }^{1}$ This week Lord Brain and Lord Hill of Luton launched an appeal at the Royal College of Physicians for $£ 750,000$ to finance research into the disease. The Trust hopes to establish a sixteen-bed in-patient unit for the study of patients before, during, and after an attack. In addition, it suggests that research fellowships should be set up at different centres-probably five. With the help of the Medical Research Council an epidemiological survey into migraine has already started in the
Rhondda Valley, while another is planned for Scotland under the auspices of Glasgow University.

Previous research has been closely tied to attempts at therapy. Thus C. Tzanck's report ${ }^{2}$ of the efficacy of ergotamine tartrate in the relief of the disorder, followed by that of W. G. Lennox and T. J. C. von Storch, ${ }^{3}$ led J. R. Graham and $H$. G. Wolff ${ }^{4}$ to carry out their experiments on the mechanisms of migraine headache. Their view that the headache itself is due to vasodilatation is now generally accepted, as is the idea that ergotamine is effective because it counters the dilatation of the blood vessels. The reason for the nausea and vomiting, which is a feature of some attacks, is more obscure, and some doubt also exists about the precise cause of the prodromal visual and sensory phenomena. Most workers hold the view that these are due to a period of vasospasm preceding the dilatation, but some believe they may owe their origin to cortical excitation of a kind seen in epilepsy. The susceptibility of some sufferers from migraine to photic stimulation has been advanced in support of this theory, but the pace of evolution of an attack is not that of an epileptic seizure.

To these early basic findings A. M. Ostfeld and colleagues ${ }^{5}$ later added the discovery that during an attack of migraine a substance is elaborated locally, at least in the perivascular extracranial tissues, which damages these tissues and lowers the threshold to pain in them. These perivascular tissues contain increased amounts of one or more amino-acids during the attack of migraine. The chemical nature of this harmful agent is still unknown, and acetylcholine, histamine, serotonin, bradykinin, and neurokinin have all been considered possible. Recently serotonin has been thought the most probable candidate, and, since 1-methyl, D-lysergic acid butanolamide (methysergide, Deseril) was evolved as an inhibitor of the action both of histamine and of serotonin, F. Sicuteri ${ }^{6}$ tested its effects in treatment of the attack and prophylaxis. $\mathrm{He}$ found it of little value in relieving a headache once begun, but of benefit in the prevention of attacks. Reports on larger series of patients followed, ${ }^{78}$ and they showed the prophylactic efficacy of methysergide but also certain side-effects. These included such grave hazards as severe peripheral vasoconstriction and retroperitoneal fibrosis, ${ }^{9}$ which though infrequent are none the less alarming.

A second line of approach followed the successful treatment reported with progestogenic steroids. The contemporary favourite is 6- $\alpha$-trifluoro-methyl 17- $\alpha$-acetoxyprogesterone (Demigran), which appears to be rather more efficacious in Scandinavia than in other countries, a difference that may be due to prescribing in higher dosage. The use of progestogenic steroids stems from the reputed value of progesterone in the treatment of premenstrual migraine. However, Demigran is said to be helpful in all types of migraine in both men and women, ${ }^{10}$ a conclusion which seems only to confuse any rational interpretation of the physiological problems and

\footnotetext{
1 Brit. med. F., 1966, 1, 230.

2 Tzanck, A., Bull. Soc. méd. Hôp. Paris, 1928, 52, 1057. 3ennox, W. G., and von Storch, T. J. C., F. Amer. med. Ass., 1935,

Graham, J. R., and Wolf, H. G., Ass. Res. nerv. Dis. Proc., 1937, 18, Ostfeld, A. M., Chapman, L. F., Goodell, H., and Wolf, H. G.,
Psychosom. Med., 1957, 19, 199.

- Sicuteri, F., Int. Arch. Allergy, 1959, 15, 300.

' Graham, J. R., New Engl. f. Med., 1960, 263, 1273.

${ }^{8}$ Friedman, A. P., and Losin, S., Arch. Neurol. (Chic.), 1961, 4, 241.

- Brit. med. 7., 1966, 1, 755.

10 Lundberg, P. O., Int. Congr. Neurol. Sci., 1965, 4, 407.

1 Miller, H. G., Prescribers fournal, 1965, 5, 74.
} 
to run counter to the idea that the basic disturbance is a hormone imbalance. Yet another authority ${ }^{11}$ has recently advocated Gower's mixture, that "nauseous triumph of Victorian polypharmacy," as a prophylactic agent, but it is difficult to see there any clue to further research.

Can there ever be an annus mirabilis for migraine research? Is a unitary concept of this disorder possible? Volumes have been written about the factors which underlie the attacks of migraine, but both careful study of it and experience with any large group of patients lead to the inescapable conclusion that on a basic constitutional tendency to these episodic disturbances are superimposed trigger mechanisms. These include stress, hormone imbalance, sensitivity to light, infections, and food allergies. We know, too, that migrainous attacks may be the result of tumours, aneurysms, angiomata, and hypertension. In short, in the term "migraine" we have a syndrome with a variety of causes. When launching the appeal Lord Brain expressed the belief that with electronic and other new research techniques the prospects of securing results had become, for the first time, more definite.

Some special migraine clinics have been set up in Great Britain and abroad. Though attractive as a means of concentrating attention on a given problem, clinics for the treatment of a single disease have the disadvantage that diagnostic investigations may be too restricted. There is indeed much to be said for making clinical research into migraine a part of general medical or perhaps neurological work, with the diagnosis of cases and investigation of the problems being carried out in a well-staffed, up-to-date neurological department.

The Migraine Trust deserves the fullest support in its efforts to tackle this common and crippling disease.
Against these gains must be set some disadvantages of the arrangements in Britain. Because of their cost really large schemes, such as new buildings, can usually be undertaken only by the Medical Research Council. Virtually all the organizations give short-term funds, and aim to establish a unit which is then taken over by a university. But most of the university funds are already committed to existing projects, and often a lot of time has to be spent finding money to keep a promising unit going. This uneasy transition period, when often neither doctors nor technicians know where their salaries are to come from in the future, shows the British set-up at its weakest. Another discouraging feature is that, because money from all sources is very scarce, the research organizations tend to back the established worker in a known field rather than the unknown, untried, young man with just a promising project.

As the conference concluded, research workers in Britain manage to do a lot with a small amount of money. But this does not mean that the system should not be changed if necessary-for example, since American workers favour a direct approach to Congress, should a trial be undertaken whereby some units are allowed to approach the University Grants Committee directly ? Nevertheless, the nub of the problem is the small amount of money actually availableemphasized by Professor Henry Miller's point that more is spent on neurological research in Boston than in the whole of Great Britain. Sooner or later the high costs of medical research must be faced by the country-for example, an established research worker, together with his technician and equipment, costs $£ 8,000$, while on average a square foot of laboratory space costs $£ 10$. Surely a country where enørmous sums of money are spent annually on gambling, tobacco, and alcohol can afford to spend more than under 10s. a head a year on medical research ? Despite the country's economic position more money must be found-and soonif our standards of medical treatment and training are not to fall.

\section{Paying for Research}

Today both our hospital service and medical education are under critical scrutiny. Yet, though medical research cannot be divorced from either, relatively little is heard of its needs, and the conference held in London last week (which is reported at p. 1353 of this week's B.M.F.) was therefore a timely reminder that the subject must not be neglected.

In Britain money for medical research comes from three main sources-the Medical Research Council and the universities (about $£ 13 \mathrm{~m}$. each annually), and private bodies, including independent foundations, charitable funds, and the drug industry (altogether about $£ 4 \mathrm{~m}$. annually). There are some definite advantages in this arrangement. First, there is the independence which the interposition of the University Grants Committee between the universities and the Government confers on the former. Secondly, the existence of a number of grant-giving organizations ensures some muchneeded flexibility, so that research workers who fail to get funds from one source may succeed by trying another. Thirdly, as several speakers at the conference pointed out, the Medical Research Council is a model of its kind, whose structure and methods have been widely copied, not only by private foundations in Britain but also by a number of official organizations in other countries. It has an enviable reputation for economical and efficient administration and farsighted scientific direction.
The unique hospitality that Edinburgh University extended to Polish medical men twenty-five years ago, during the second world war, is being commemorated there next week. With their country in ruins and its people terrorized or dead, remnants of the Polish Army reached Great Britain from France in 1940. A number of their leading medical men were with them, and to Professor (then Lieutenant-Colonel) F. A. E. Crew they owe the brilliant idea of a medical school for Poles in Edinburgh. The University responded generously, and, as Professor J. Rostowski records in the B.M.7. this week (p. 1349), the Polish School of Medicine was inaugurated in 1941 with its own constitution and staff. 'In all, 228 students graduated from it before it was finally closed in 1949 .

As all who were associated with the Poles on battlefields during the war will know, their dramatic courage was unsurpassed anywhere. That same spirit gave them the resilience to build up their medical services in the strange though friendly surroundings of our northern capital. After the war many of the Polish doctors who had qualified in the Edinburgh School chose to remain in Britain, and we may indeed be grateful to them for thus helping to fill the gaps in our own services. 